
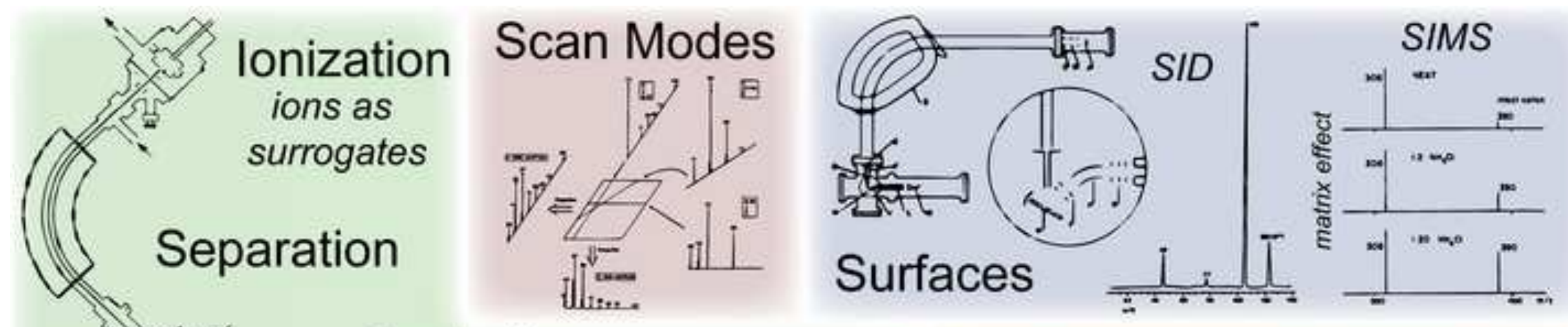

Analysis energy and mass
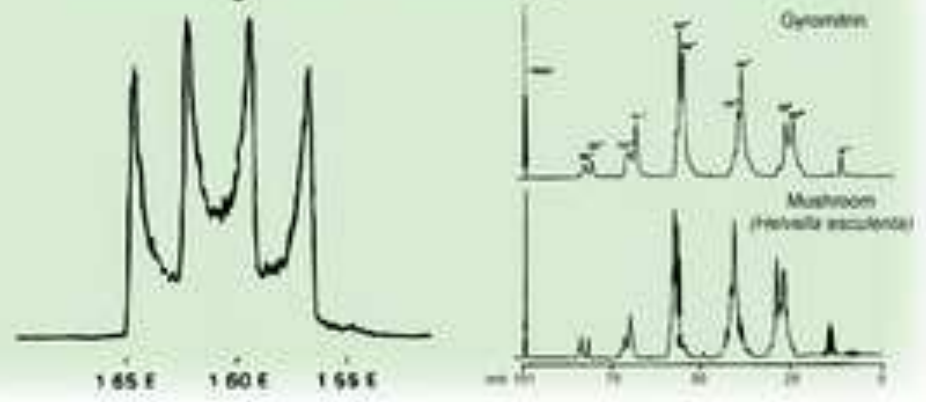

Ion Chemistry breakdown curves
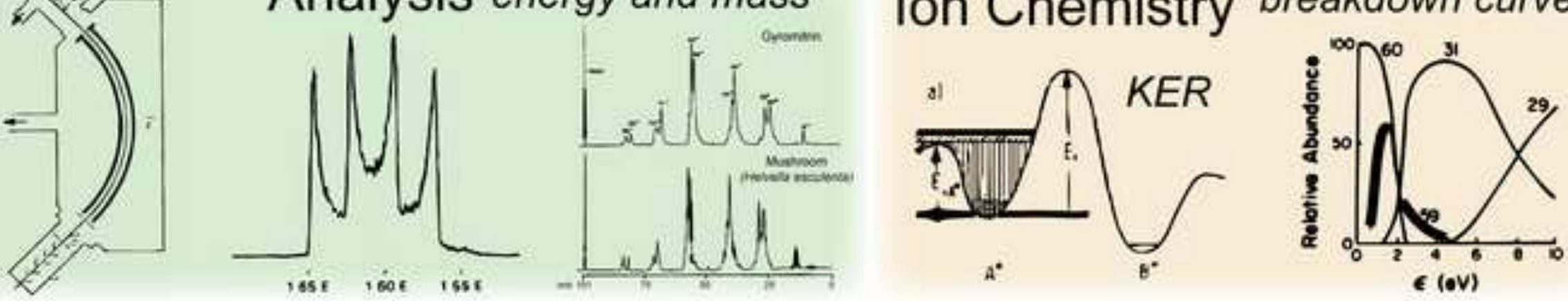


\title{
Direct analysis of complex mixtures by mass spectrometry
}

\author{
R. Graham Cooks, Alan K. Jarmusch and Michael Wleklinski \\ Department of Chemistry and Center for Analytical Instrumentation Development, Purdue University, \\ West Lafayette, IN 47907
}

\section{Keywords $(\max 6)$}

tandem mass spectrometry, energy transfer, ion/surface collisions, metastable ions, ion kinetic energy, fragmentation, historical

\begin{abstract}
Mixture analysis can provide information on individual components if the sample is first subjected to chromatographic separation. Two critical capabilities, soft ionization and the ability to mass-select and then dissociate ions of a particular $m / z$, coalesced in 1975, allowing direct analysis of complex mixtures by mass spectrometry. Chemical ionization was used as the soft ionization method and mass-analysis used the ion kinetic energy spectrometer (MIKES). Soft molecular ionization produces a set of ions that are structural surrogates of the neutral molecules; they can be mass-selected and allowed to spontaneously dissociate (i.e. as metastable ions) or fragmented upon energy transfer e.g. in the course of collision-induced dissociation (CID). The second stage of mass analysis provides information about the atomic connectivity in the precursor ion and by implication in the original molecule. This review focuses on the development of complex mixture analysis by mass spectrometry and allied topics. Discussion of the activation techniques associated with (collision-induced dissociation, surface-induced dissociation and metastable ion dissociation) emphasizes the importance of energy transfer phenomena and the internal energies distributions of ions to explain the observed mass spectra. The translational to internal energy transfer in collisions is readily accessed in the MIKES where the second stage mass analyzer is a kinetic energy/charge analyzer. Collisions in the keV range can also be used to change ion the charge state via the processes of charge exchange, electron stripping, or charge inversion. New ionization sources for analysis of non-volatile compounds that were introduced during the time period (1975 1990) of this review included secondary ion mass spectrometry, plasma desorption and field ionization and they are briefly discussed. Several types of scans were developed to rapidly access information of the individual components, including chemically specific scans (e.g. neutral loss scans of mass 30 for nitro compounds).
\end{abstract}




\section{Introduction}

In 1975 two capabilities came together to allow direct, rapid analysis of complex mixtures of organic compounds by mass spectrometry. They were (i) mass-analyzed ion kinetic energy spectrometry, MIKES, a method of characterizing ions of given $\mathrm{m} / \mathrm{z}$ ratio by isolating them from a mixture of ions and then performing an operation, typically collision-induced dissociation (CID), that generated a characteristic set of fragment ions from each precursor ion and (ii) chemical ionization (CI) a method of ionization that allowed control of ion internal energy including the ability to cause soft ionization so as to minimize fragmentation during ion formation. Together these two capabilities allowed a complex mixture of neutral molecules to be separated into a mixture of ions, the structures of which reflected those of the original compounds in the mixture. When ions of particular $\mathrm{m} / \mathrm{z}$ ratios were selected from the ionized mixture by mass analysis and then subjected to CID, a secondary mass spectrum would be recorded from which the nature (connectivity) of the corresponding neutral molecule could be inferred. This process depended on creating an ionic surrogate of each neutral compounds of interest; to do this successfully, ionization had to be gentle. To identify the selected ion, characteristic fragment ions needed to be generated and this was originally achieved by CID in the keV energy regime. This paper details these developments and associated advances in generating and characterizing molecular ions through gas-phase and surface collisions over the period 1975 - 1990.

\section{MIKES instrument}

The design and operation of the mass-analyzed ion kinetic energy spectrometer (MIKES) represented a sharp break from the path being taken by primary body of MS work being performed at the time. This mainstream work achieved high mass resolution using double focusing (magnetic and electric sectors) in the keV energy range. Although the same two-sector instrumentation was used, the positions of the magnetic and electric sectors were reversed, and they were uncoupled instead of being using in concert to improve mass resolution. Successive ion kinetic energy and mass analysis performed on a ion beam, allowed spontaneous or collision-induced processes occurring in the region between the sectors to be characterized by kinetic energy analysis (equivalent to mass analysis but only at constant velocity). ${ }^{1}$ McLafferty $^{2}$ also uncoupled a two-stage instrument by reversing the positions of source and detector of a Hitachi Perkin-Elmer RMU-7 while at MAT in Bremen (later FinniganMAT and still later Thermo) Curt Brunneé used a reversed geometry instrument to study direct analysis of daughter ions (DADI). Significantly, but not known to community of organic mass spectroscopists, Fred White ${ }^{3}$ had already built three- and four-sector instruments to perform beam/foil collision experiments to characterize small ions by fragmentation and Futrell and Tiernan ${ }^{4}$ had constructed a four-sector tandem instrument to study at very low energy the reactions of mass-selected ions.

Completed in 1973 in the reverse-geometry format, (electric sector/magnetic sector) the MIKES instrument ${ }^{5}$ allowed spontaneous dissociations as well as inelastic collisions of mass-selected ions to be studied. The resulting ion kinetic energy spectra allowed both the mass changes involved and more subtly, translational energy changes, to be measured. The fabrication of components for the MIKES instrument fell upon Tom Ridley, the skilled machinist at Purdue University. Tom recalled that the MIKES instrument was presented to him as a hand-drawn sketch on a single sheet of paper. The ion optics was 
based on calculations provided by Syd Evans of AEI (later Kratos). The vacuum system and electronics fell to the expertise of William Baitinger and Jonathan Amy, ${ }^{6}$ whose Instrumentation Facility (now the Jonathan Amy Facility for Chemical Instrumentation), continues to design and fabricate instrumentation in support of Purdue researchers.

\section{Physical chemical studies using MIKES}

MIKES allows precursor ions to be mass-selected in the magnetic sector and product ions to be mass analyzed using the electric sector. Operated normally, the electric sector measures ion kinetic energy-tocharge ratios; however, at constant ion velocity, $\mathrm{m} / \mathrm{z}$ values can be inferred. This is the basis for the analytical MS/MS experiments done using this instrumentation and discussed further below. For ions of the known mass, the electric sector measures ion velocities which form the basis for studies of the kinematics of various collision processes. Kinematics is conveniently displayed as vectors in Newton diagrams where the origin is the center of mass of the system. ${ }^{7}$ This methodology allows elastic collisions to be distinguished from more or less deeply inelastic processes through velocity measurements whether these involve reaction or fragmentation.

The study of metastable ions - ions that spontaneously dissociate at some time after their formation was greatly enriched by MIKES measurements. Metastable peaks had first been reported in 1946 by Hipple, Fox, and Condon ${ }^{8}$ as the signals due to the spontaneous dissociation of ions with excess internal energy above the dissociation threshold. Excess energy is converted into vibrational, electronic, and translational energy of product ions - the latter corresponding to kinetic energy release. The kinetic energy release of metastable ions revealed details about ion structure, reaction energetics and dynamics. The fact that wide peaks are observed in MIKES (Figure 1) is due to velocity amplification of the kinetic energy release in the fast moving fragments, an effect associated with measuring in the lab system processes that occur in the simpler center-of-mass coordinate system. Note that the reverse process is also possible in that translational energy can be converted into excess internal energy resulting in dissociation (e.g. collision induced dissociation) and this shows up as velocity shifts in Newton diagrams. The study of metastable ions, energy conversion (T-V) upon collisional activation and kinetic energy release ( $\mathrm{V}-\mathrm{T}$ ) upon fragmentation, kinetic isotopic effects, mapping of potential energy surfaces for ion dissociation, measurements of thermochemical properties and of unimolecular kinetics were just some of the capabilities of this powerful device as detailed elsewhere. ${ }^{9}$

As a specific example, the reverse critical energy for a unimolecular dissociation ( $\varepsilon_{0}{ }^{*}$ in Figure $\left.1 a\right)$ is large and a significant fraction is released as kinetic energy $\left(\mathrm{T}^{\neq}\right)$when reaction proceeds via a tight transition state as is often the case for skeletal rearrangements. ${ }^{10}$ On the other hand, loose transitions, such as those corresponding to simple bond cleavage, require very little rearrangement in the transition state possess negligible reverse activation energies and are associated with small kinetic energy releases. Therefore, qualitative information on the nature of the transition state for ionic dissociations is available from MIKES via peaks shape and kinetic energy release measurements. ${ }^{11}$ Kinetic energy release can vary between isotopomers, resulting in different peak shapes in MIKES. For example, ions with the chemical group ( -HCD- ) fragmenting with loss of the heavier isotope give the smaller kinetic energy release. This is because the zero point energy of the product is slightly greater. ${ }^{12}$ Small differences between chiral 
ions were noted in the late $1970 \mathrm{~s},{ }^{13}$ while a method based on kinetic energy release between chiral ions followed much later. ${ }^{14}$ Competitive fragmentations in MIKES also proved useful in investigating ion thermochemistry, importantly competitive metastable ion fragmentation allow the estimation of proton and other ion affinities by what has come to be known as the kinetic method. ${ }^{15}$

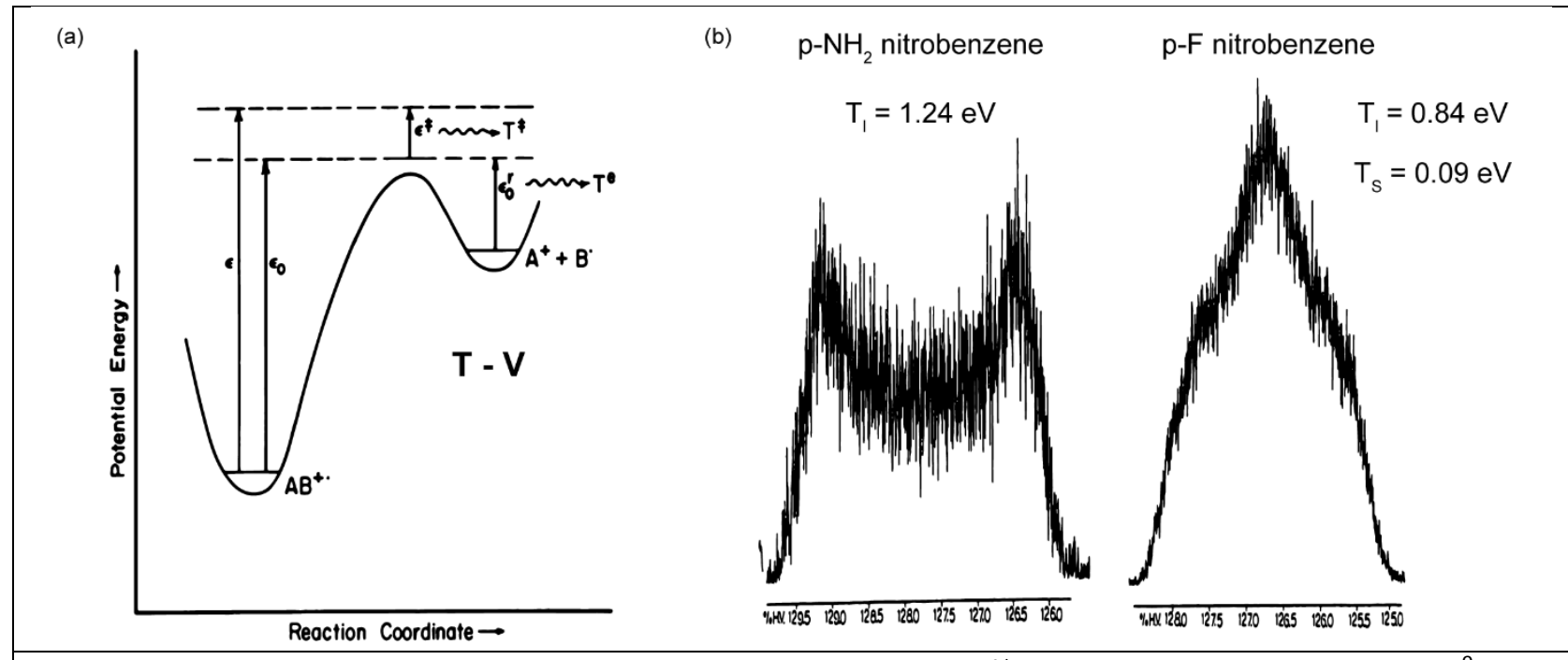

Fig 1. (a) Reaction coordinate of an ionic dissociation of $A B^{\circ+}$ [reproduced from reference ${ }^{9}$. (b) Composite metastable peaks for the $\mathrm{NO}^{\circ}$ loss from $\mathrm{p}$-substituted nitrobenzene $\mathrm{p}-\mathrm{NH}_{2}$ (left) and $\mathrm{p}-\mathrm{F}$ (right), where $T_{I}$ and $T_{s}$ refer to the kinetic energy release values of the separate reaction pathways which contribute components to the composite peak. [modified from reference ${ }^{16}$ ]

\section{MS/MS using MIKES}

Chemical ionization was a recently commercialized method when a $\mathrm{Cl}$ source was installed on the MIKES instrument at Purdue in 1975 by scientists from Scientific Research Instruments of Baltimore, including Marvin Vestal, later of renown in the LC/MS and TOF/TOF fields. The plan to add $\mathrm{Cl}$ to what was essentially a physical chemistry instrument was driven by the desire to perform direct analysis of complex mixtures, especially of plant material for alkaloids. This topic had been the subject of the Ph.D. research of the senior author a decade earlier. That earlier work had been done at a time when spectroscopic analysis was limited in scope and, in the absence of chromophores to give uv-vis features, chemical methods of characterization were the main structural tools available. This author's University of Natal Ph.D. thesis was in some peril until a visitor, Carl Djerassi, took an interest in the work and had a mass spectrum recorded by Dudley Williams (a post-doctoral at Stanford). This gave explicit structural information on the main alkaloid, a bis-disulfide.

After the addition of the $\mathrm{Cl}$ source to the MIKES, there followed a period of intense activity in which complex samples of all sorts were examined. Terry L Kruger, a visiting professor from Ball State University played a significant role in tackling a range of materials. The major emphasis was on plant material, especially cacti, the specialty of Jerry McLaughlin, a collaborator in Purdue's College of Pharmacy. ${ }^{17}$ The choice of whole plant material for these studies was fortunate in that alkaloids are readily ionized, containing basic amine functionalities, and their ions dominate the spectra even in the presence of many other compounds. The polymeric cellulosic materials do not interfere. Levels of the 
alkaloids are low (parts per thousand typically) but not trace. Unfortunately, the biological significance of these secondary plant metabolites was limited and so the success of the experiments attracted limited attention although it did serve as an exemplar of what could be done by MS/MS in systems of greater biological significance.

Internally, in what was now to be known as the Aston Laboratory for Mass Spectrometry, the excitement mounted with the successful application of the MIKES experiment (see Table 1) to every conceivable type of complex mixture - plant leaves, nutmeg, strawberry jelly, and urine. The results were disseminated in a series of seminars over the next five years which tended to divide audiences sharply. There was a particular reluctance to accept the improvement in signal-to-noise in MS/MS where the signal was much lower than in single stage MS. This led to the introduction of the idea of chemical noise, now widely accepted, and to comparisons of MS/MS with fluorescence also a low total signal experiment typically with better signal/noise characteristics than simple absorption. At the time, technological developments in chromatography/MS combinations and improvements in high resolution MS were occurring. In these pre LC/MS days, the advantages of the GC/MS combination were clear, separation prior to MS providing pure compounds to the MS. This was achieved at a cost in terms of time and complexity, then as now. The pivotal point in the campaign for acceptance of direct mixture analysis as a significant tool came with Rick Yost and Chris Enke's implementation of low energy CID on the triple quadrupole ${ }^{18,19}$ vigorous contributions to its utilization came from Don Hunt ${ }^{20-22}$ while Fred McLafferty who had long used tandem instrumentation to characterize ion structures was a welcome ally to the subject what then came to be known as MS/MS. ${ }^{23-25}$

Table 1. Progress of Complex Mixture Analysis by Mass Spectrometry

\begin{tabular}{|c|c|}
\hline Topic & Year \\
\hline Direct Mixture Analysis by MIKES ${ }^{26}$ & 1976 \\
\hline Identification of alkaloids in crude extracts by MIKES ${ }^{17}$ & 1977 \\
\hline Alkaloids in Whole Plant Material: Direct Analysis by Kinetic Energy Spectrometry ${ }^{27}$ & 1978 \\
\hline Direct Mass Spectrometric Mixture Analysis by Negative Ion MIKES ${ }^{28}$ & 1978 \\
\hline Direct Analysis by MIKES Using Negative Chemical Ionization ${ }^{29}$ & 1978 \\
\hline Mixture Analysis by Mass Spectrometry ${ }^{28}$ & 1978 \\
\hline Multiple Reaction Monitoring in Mass Spectrometry/Mass Spectrometry for Direct Analysis of Complex Mixtures ${ }^{30}$ & 1978 \\
\hline Selected ion fragmentation with a tandem quadrupole mass spectrometer ${ }^{18}$ & 1978 \\
\hline Identification of Individual Steroids in Biological Matrices by MIKES ${ }^{31}$ & 1979 \\
\hline Analysis of Coal Liquids by Mass-Analyzed Ion Kinetic Energy Spectrometry ${ }^{32}$ & 1979 \\
\hline Mapping of Cocaine and Cinnamoylcocaine in Whole Coca Plant Tissues by MIKES ${ }^{33}$ & 1979 \\
\hline Mixture Analysis by Mass Spectrometry ${ }^{34}$ & 1979 \\
\hline Triple quadrupole mass spectrometry for direct mixture analysis and structure elucidation ${ }^{19}$ & 1979 \\
\hline Rapid Analysis of Complex Mixtures by Mass Spectrometry/Mass Spectrometry ${ }^{35}$ & 1980 \\
\hline Chemotaxonomy of Columnar Mexican Cacti by Mass Spectrometry/Mass Spectrometry ${ }^{36}$ & 1980 \\
\hline A Double Quadrupole for Mass Spectrometry/Mass Spectrometry ${ }^{37}$ & 1980 \\
\hline Ion Structure Determinations and Ion-Molecule Reactions by Double Quadrupole Mass Spectrometry ${ }^{38}$ & 1980 \\
\hline Collision activated decompositions in mixture analysis with a triple quadrupole mass spectrometer ${ }^{20}$ & 1980 \\
\hline Analysis of Synfuels by MS/MS ${ }^{39}$ & 1981 \\
\hline Tandem Mass Spectrometry ${ }^{24}$ & 1981 \\
\hline Consecutive Reactions in Triple Analyzer Mass Spectrometry and Applications to Mixture Analysis ${ }^{40}$ & 1982 \\
\hline $\begin{array}{l}\text { Cactus Alkaloids, XLIX. New Trace Alkaloids (Dehydrosalsolidine and Heliamine) from the Saguaro, Carnegiea Gigantea, and } \\
\text { Confirmation by MIKES (MS/MS) }\end{array}$ & 1982 \\
\hline
\end{tabular}




\begin{tabular}{|l|l|}
\hline Direct Characterization of Nutmeg Constituents by MS/MS & 1982 \\
\hline $\begin{array}{l}\text { High and Low Energy Collision Mass Spectrometry/Mass Spectrometry of Aza and Amino Polynuclear Aromatic Compounds in } \\
\text { Coal-Derived Liquids }\end{array}$ & 1982 \\
\hline Mixture analysis by triple-quadrupole mass spectrometry: metabolic profiling of urinary carboxylic acids & \multicolumn{1}{|c|}{1982} \\
\hline Determination of organosulfur compounds in hydrocarbon matrixes by collision activated dissociation mass spectrometry & \multicolumn{1}{|c|}{1982} \\
\hline
\end{tabular}

\section{Ion activation, dissociation, and/or reaction}

The origins of CID go back to earliest days of MS, with fragments generated by inadvertent fragmentation in poor vacuum systems being seen even in Thomson's parabola instrument. ${ }^{44}$ Note that in the Soviet Union too, the atomic energy program and interest in isotopes had also led to investigations of ion dissociation through high energy collisions especially in the work of Kupriyanov. ${ }^{45}$

In the special case of sector field mass spectrometers consisting of an electric sector (E) and a magnetic sector (B), the usual implementation of MS/MS for complex mixture analysis requires that dissociation or reaction of the precursor ions of interest occur after the first stage of mass/charge analysis and before the second stage. However, it is possible to perform linked scans of the two fields in such a way that collisions occurring after ion acceleration in the region prior to the sectors are interrogated. ${ }^{46}$ Such linked scans the two sector analyzers allow identification of all precursors of a given product ion as well as all products of dissociations of a chosen precursor.

\section{Types of scans}

Independently of the instrumentation used in principle there are only a few types of scans that can be used to interrogate the data domain resulting from tandem mass spectrometry of complex mixtures. It is interesting to note that these were not all explicitly recognized at the same time. The product ion scan (in the language of the time, the "daughter ion scan") was recognized early. In fact the MIKES instrument (and similarly the reverse geometry instrument of McLafferty) was conceived so as to record product ion spectra. Early on too Barber and Elliott ${ }^{47}$ showed that precursor ion scans could be performed using conventional ( $E$ then $B$ ) double-focusing sector mass spectrometers by scanning the accelerating voltage. This Barber-Elliott "defocusing" technique revealed signals of metastable ions associated with a selected product ion. ${ }^{48}$ The product and precursor ion scans are illustrated in the 2D full data domain, i.e. the set of all ion intensities connecting product and precursor ions as shown in Figure 2. Given this representation of the data is it easy to see that any relationship between precursor and product mass can be chosen for examination. A particularly useful relationship is the constant neutral loss scan, in which the $3^{\text {rd }}$ element of the simple equation $\mathrm{m}_{1}{ }^{+} \rightarrow \mathrm{m}_{2}{ }^{+}+\mathrm{m}_{3}$ is kept constant. This scan was not explicitly recognized until 1979 yet it has particular value in recognizing the presence of a set of related compounds in a mixture. ${ }^{49}$ This usefulness arises because particular functional groups show particular types of fragmentations - either those that give rise to the same fragment ion (as in the ion $m / z 43$, seen in acetyl derivatives) or the same neutral fragment as in the loss of 42 from acetylated compounds. In an important paper from 1990, Enke, Cooks and coworkers ${ }^{50}$ laid out the formal rules for scans of different types in MS experiments of zero to $\mathrm{n}$ stages of mass analysis, viz. a formal zero mass $\mathrm{DOF}$, a single mass variable, and also the MS/MS and in general $\mathrm{MS}^{\mathrm{n}}$ experiments. In this analysis there is one $2 \mathrm{D}$ experiment and this is the full data domain. There are three one-dimensional (in mass) 
experiments, the precursor, product and neutral loss scans already discussed. There is also one type of experiment that is zero dimensional in mass, that in which both $m_{1}$ and $m_{2}$ are specified (and automatically also $m_{3}$ which is simply the difference between $m_{1}$ and $m_{2}$. This experiment was named the single reaction monitoring (SRM) experiment ${ }^{30}$ by analogy with single ion monitoring (SIM) the zero mass dimensional experiment that could be done in chromatography/mass spectrometry experiments like $\mathrm{GC} / \mathrm{MS}$. If as is common, more than one transition is of interest the experiment is referred to as multiple reaction monitoring (MRM). ${ }^{30}$ This experiment has become a mainstay of quantitative work in mass spectrometry. It has the advantage of being fast because it is not necessary to investigate the intensities of ions that are not of interest - one simply sets up the instrument to observe the ions that are of interest. In addition, it has good specificity because a particular compound is specified by two characteristics, a precursor and a product mass. An early example of MRM and a calibration curve for quantification of cocaine is shown in Figure 3.
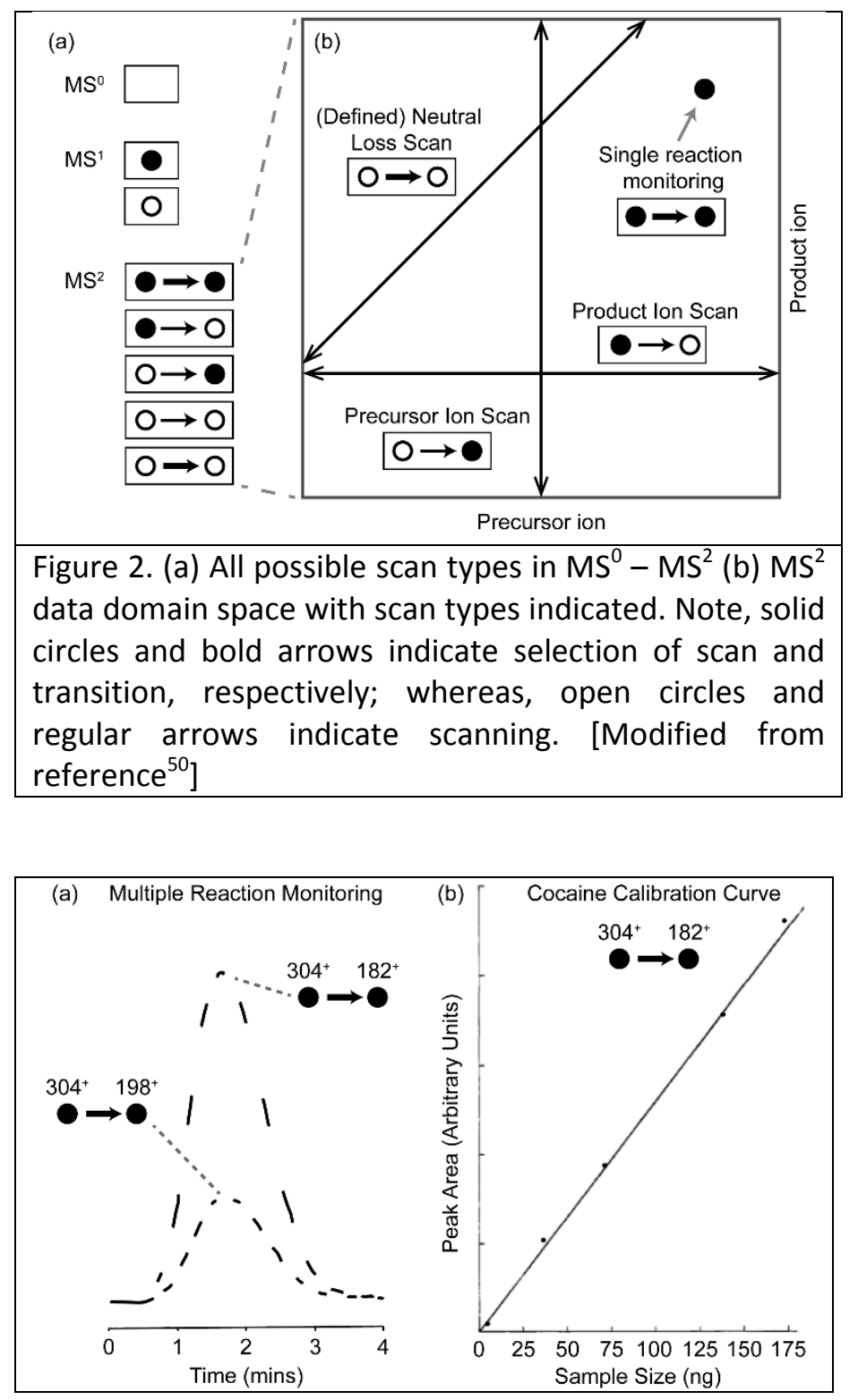
Figure 3. (a) MRM scan for two precursor/fragment pairs of cocaine obtained from coca plant leaf produced by Cl-MIKES. (b) Calibration curve for cocaine for a single transition ( $\mathrm{m} / \mathrm{z} 304$ to $\mathrm{m} / \mathrm{z}$ 182). [Modified from reference $^{30}$ ]

The reader is referred to the paper in this issue by Keith Jennings [K.R. Jennings publication in this issue, IJMS 2014] on collision-induced fragmentation for a description of the origins and basis of the methods of creating and observing the products of fragmentation. Jennings also describes the alternative dissociation methods of electron capture dissociation (ECD), electron transfer dissociation (ETD) and surface-induced dissociation (SID).

This last method is of some interest in the wider context of ion/surface collision phenomena. ${ }^{51-53}$ These phenomena include simple inelastic scattering as well as reactive scattering and the gentle deposition of polyatomic ions at surfaces, known as ion soft landing. Figure 4 illustrates these processes in the chemically interesting range of collision energies. Inelastic scattering of an ion from a surface, results in deposition of internal energy into the scattered ion and this can lead to subsequent molecular dissociation depending on the rate constant for the various dissociation channels and the time allowed by the ion velocity. SID originally reported in 1975 was implemented in a routine fashion a decade later as a complementary technique to CID. ${ }^{54-58}$ The energy partitioned into internal energy in SID typically has a higher average value and a narrower distribution of values than is the case for single collision CID in the keV energy range and is narrower than is the case for low energy CID. While energy transfer is also angle dependent (see below) a rough rule of thumb for low angles is that 'hard targets' like diamond and self-assembled fluorinated hydrocarbon monolayers (F-SAM surfaces) partition some $25 \%$ of their translational into internal energy. Softer surfaces like hydrocarbon SAMs partition about half this amount into internal energy of the activated ions. If the collision energy is reduced to the low hyperthermal range $(<10 \mathrm{eV})$ soft landing $(\mathrm{SL})$ of polyatomic ions onto the same F-SAMs and H-SAMs is possible. ${ }^{59} \mathrm{~A}$ fascinating aspect of $\mathrm{SL}$ is the ability of deposited ions to retain their charge for hours or even days on the appropriate surface. ${ }^{60}$ The pathways for neutralization are proton transfer or electron transfer depending on the type of deposited ion (protonated vs. precharged ion). Compared to other surface preparation techniques, SL allows for the deposition of materials with high chemical purity, which is useful for the preparation of catalysts ${ }^{61}$ or protein microarrays. ${ }^{62}$ It also allows the deposited ion to be examined in detail by atom probe methods. ${ }^{63,64}$

The occurrence of reactions during an ion/surface collision parallels the occurrence of reactions during ion/gas or molecule collisions. Such reactions reflect information on the nature of the reacting partners and as such potentially have value in chemical analysis, at least in terms of providing qualitative information on the nature of the ionic reagent. This has long been realized and in the case of ion/molecule reactions has been one driving force in the development of methodology and instrumentation for their study. However, chemical reactivity is less easily converted into structurally diagnostic information than is a knowledge of fragmentation processes and these efforts have not flourished. The dependence of reactivity on internal energy is one reason for this as is the fact that the reaction products are often not generated in great variety, limiting the purely analytical information. 
None of this takes away from the importance of the study of gas-phase ion molecule reactions or the richness of that chemistry. ${ }^{65-68}$ lon/surface reactions have also been studied extensively, often in an attempt to seek reactions that are characteristic of certain functional groups in the ions. ${ }^{51,52,69}$ Again, much interesting chemistry has been elucidated but the contributions to ion characterization are limited.

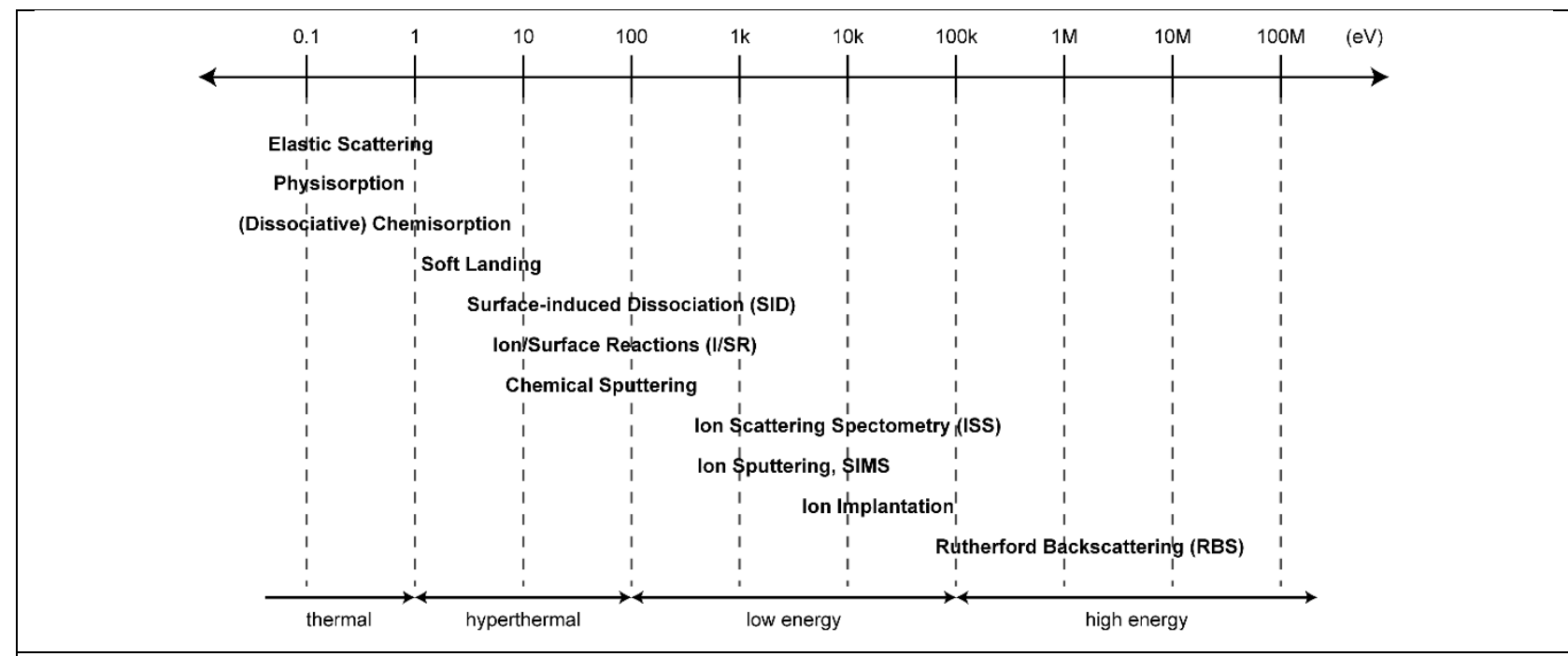

Figure 4. Fundamental molecule/surface collision processes from thermal to high energy collision noted in general range in which processes typically occur. [Adapted with permission from reference ${ }^{70}$ ]

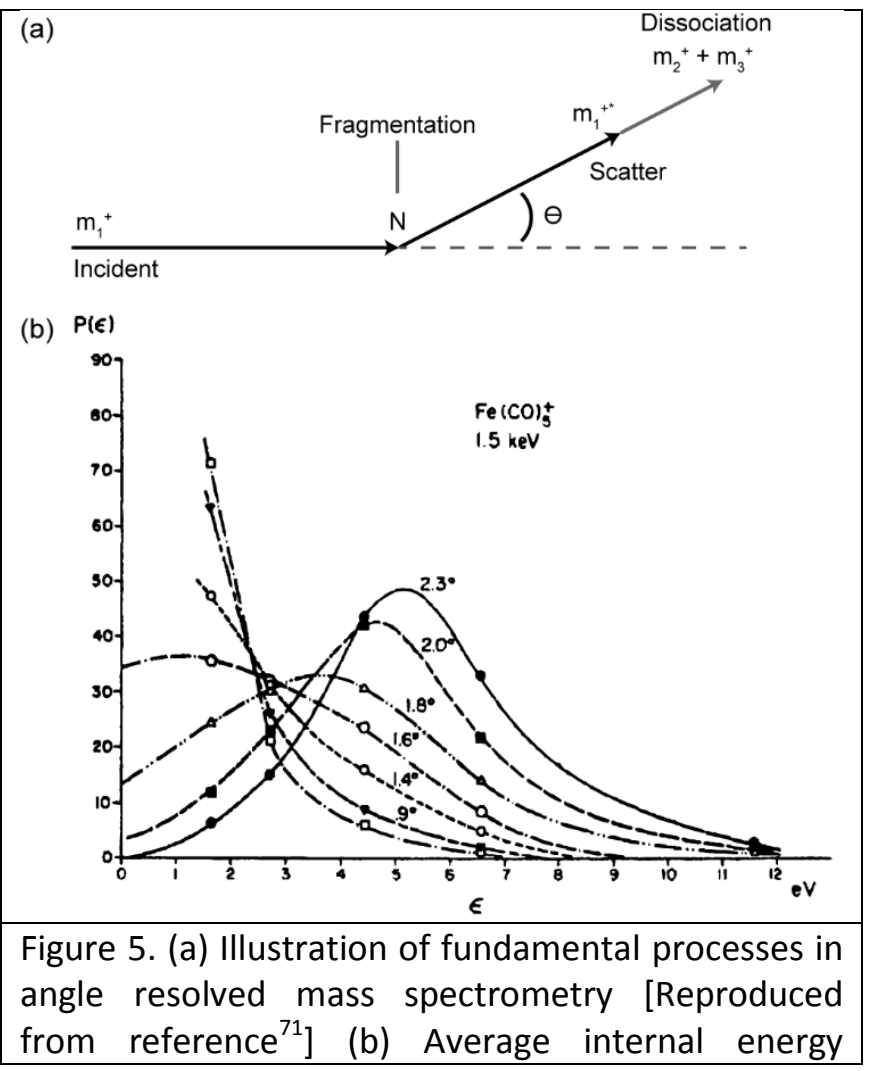


increases with increased scattering angle demonstrating angle/energy transfer relationship. [modified from reference ${ }^{72}$ ]

The relationship between scattering angle (in the lab frame of reference), Figure 5, and internal energy deposition in a polyatomic ion can be used to readily (if not very accurately) observe fragment ions due to precursors that have been excited to different extents. This measurement, referred to as angle resolved mass spectrometry has to be made on a mass spectrometer capable of accessing ions scattered into different directions. For beam energies in the keV range the scattering angles involved are very small, typically less than $1^{\circ}$ (lab) allowing modified sector instruments to be used. (By contrast the study of ion/molecule reactions requires instruments capable of angular and kinetic energy resolution over a wide range. ${ }^{73,74}$ ) Figure 5, illustrates the internal energy distributions at particular scattering angles and the increase in energy deposition with angle.

\section{Internal energy distributions}

The importance of the distribution of internal energies in a population of ions is evident from the above discussion of activation and dissociation. Because it is so central a topic in mass spectrometry, some further comments on its importance and the development of its understanding might be useful. By the early to mid - 1960's an understanding of unimolecular fragmentations of ions had been developed and formulated as the quasi-equilibrium theory (a version of transition state theory in which the 'equilibrium' refers to activated ion/activated complex, viz. transition state, equilibrium). This formalism explained reaction rates and allowed mass spectra to be calculated in combination with (i) knowledge of fragmentation pathways (represented by the full fragmentation pattern), (ii) the reaction time scale and (iii) the internal energy distribution. The basic understanding was provided by the work of Chupka, ${ }^{75}$ Wahrhaftig, Rosenstock ${ }^{76}$ and others. A parallel, more extensive development of understanding of kinetics for neutral molecules saw rapid expansion with the development of molecular beams, the phenomenon of chemical activation ${ }^{77}$ and the relaxation processes that occur in higher pressure studies. (An appreciation of collisional relaxation in mass spectrometry has gradually taken hold with the increasing importance of trapped ion devices. ${ }^{15,78}$ ) It should be clear that a mass spectrum is merely a distribution of products of a set of activation/deactivation, inelastic, and some reactive collision processes, observed at some point in time. Inelastic processes are easier to deal with than mixtures of inelastic and reactive collisions, and unimolecular dissociation after collisional activation is simpler still and fortunately comprises a significant fraction of the common experiments done in mass spectrometry. A mass spectrum is a product distribution and not a particularly fundamental quantity, but the breakdown curve is a more fundamental property. A breakdown curve is a representation of the mass spectrum for a particular ion, obtained from the known rate constants and at a particular time and for a particular internal energy. Convolution of the breakdown curve over an internal energy distribution, $P(\varepsilon)$, gives the mass spectrum.

The internal energy distribution, $\mathrm{P}(\varepsilon)$, is of central importance in mass spectrometry. This is illustrated by three mass spectra recorded for the same compound using ionization methods that create different 
internal energy distributions (Figure 6). These make methods of determining $P(\varepsilon)$ important also and a procedure has been developed based on 'thermometer' ions which fragment by a simple sequence of neutral loss processes and so reveal, depending on the degree to which various fragments in a sequence are represented, the internal energy distribution. An ideal thermometer ion undergoes a series of simple unimolecular fragmentations for each of which the thermochemical requirements are known. ${ }^{79}$ The assumption is then made that ions with enough energy to fragment will do so rapidly and this allows $P(\varepsilon)$ to be measured for a variety of processes, as illustrated in Figure 6.

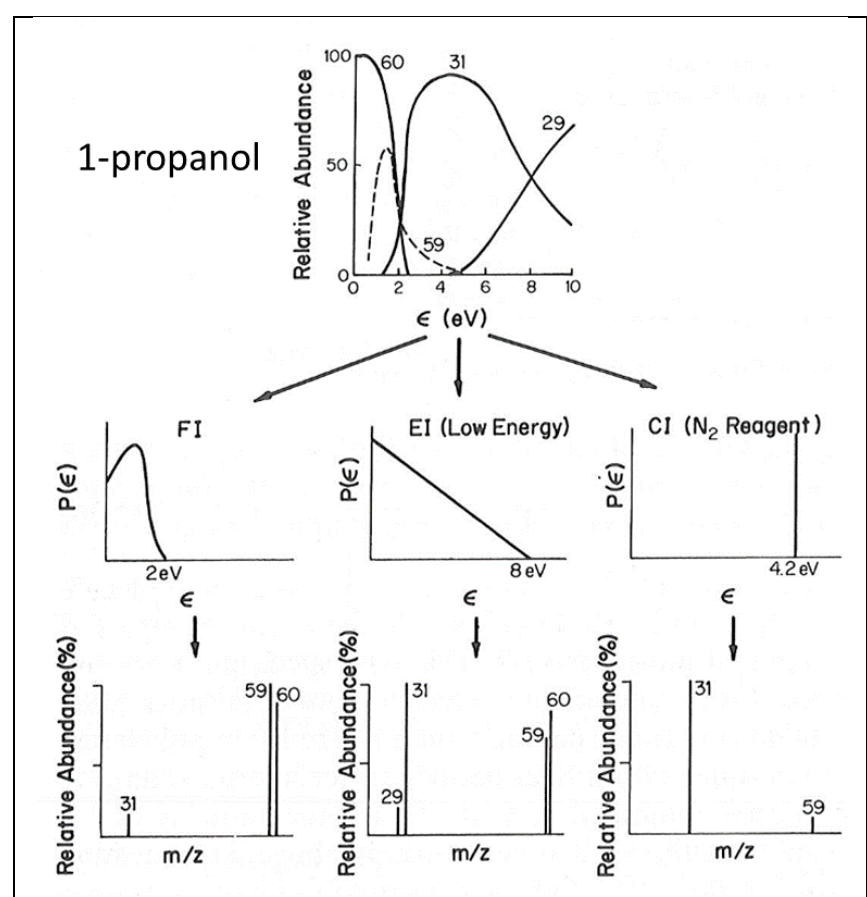

Figure 6. (Upper) Breakdown curve of 1-propanol over 0-10 eV. (Middle) Internal energy distributions of 3 ionization techniques ( $\mathrm{Fl}, \mathrm{El}$, and $\mathrm{Cl}$ ). (Lower) Mass spectra obtained from various ionization sources displaying differences in fragments observed and relative intensity. [reproduced with permission from reference ${ }^{80}$ ]

\section{Charge changing collisions}

When a complex mixture of molecules is subjected to ionization, a mixture of singly- and multiplycharged ions will often be generated. In some cases, as in electron impact of aromatic hydrocarbons or the electrospray ionization of proteins, the abundances of multiply-charged ions might be substantial. These ions are readily distinguished from singly-charged ions by the spacing of their natural carbon isotopes, which is one Thomson (unit of $m / z$ ) for singly-charged ions and $1 / n$ Thomson for ions with $n$ charges. It was realized some time ago that a scan which examined only say, doubly-charged ions might be of value in being selective of certain classes of compounds from a mixture. This can be achieved by performing a charge changing collision instead of a collision-induced dissociation. Doubly-charged ions 
are characterized by the ability to undergo partial charge exchange with a neutral reagent to give the corresponding singly-charged ions $\left(\mathrm{m}_{1}{ }^{2+}+\mathrm{N} \rightarrow \mathrm{m}_{1}{ }^{+}+\mathrm{N}^{+}\right)$. So a scan that recognizes the reaction would reveal all doubly charged ions in a mixture and hence those compounds that are preferentially doublyionized. This phenomenon is evident even in Thomson's parabolas ${ }^{81}$ and was explained in exactly this way. A scan that recognizes this type of process is readily implemented in tandem sector instruments because doubly-charged ions are accelerated to twice the kinetic energy of their singly-charged isobars and when they undergo charge exchange the resulting singly charged ions have twice the normal energy of singly charged ions. By setting the pass energy of an electric sector at twice the normal kinetic energy (2E) singly charged products of doubly charged precursors are observed while no other ions are seen. This $2 \mathrm{E}$ mass spectrum is a selective way of looking at doubly charged ions. For example, it is useful in recognizing aromatic hydrocarbons from a mixture. ${ }^{82}$ The selective scan can be performed on other types of tandem in space MS/MS instruments, for example, a triple quadrupole can be scanned so that Q3 (the second mass analyzer) is linked to the scan of Q1 (the first mass analyzer) in such a way that ions are transmitted through both analyzers if their mass/charge ratio increases by a factor of exactly two in the collision region (Q2) between the two analyzers. This is achieved by scanning Q3 at twice the rate of Q1 and this too has been demonstrated. ${ }^{83}$ It will be obvious that the same principles can be applied to look at other charge-changing collisions and the particular one that has been examined in some detail is the charge stripping reaction $\left(\mathrm{m}_{1}{ }^{+}+\mathrm{N} \rightarrow \mathrm{m}_{1}{ }^{2+}+\mathrm{N}+\mathrm{e}^{-}\right.$) monitored via $\mathrm{E} / 2$ scan (reversed geometry sector) or half speed scan (triple quad). These types of scans to interrogate complex mixtures are not widely used but they illustrate the principles of development of methods of interrogating complex samples using mass spectrometry only without benefit of chromatographic or other separation. They bring to mind more recent experiments in which classification on the basis of molecular mass defects (difference in exact mass from integral mass) have been used for classification. For example mass defect filtering can be used to remove all data outside a defined mass defect range, separating alkanes, organic acids, sugars, steroids, carotenoids, and phospholipids. ${ }^{84}$

\section{$\underline{\text { lonization Methods used in Complex Mixture Analysis }}$}

In the 1970's, organic mass spectrometry could only be performed on volatile compounds, the vapors of which were subjected to electron impact, a process that lead to electronic excitation, lonization or both. The great merit of electron ionization (EI) lay in two facts: the data were highly reproducible as they depended on the physical processes just described occurring within a set time interval. This also meant that useful libraries of El mass spectra could be generated and used in an approximately instrument independent fashion. The other advantage was that the combination of hard and soft ionization events produced by the statistical nature of the electron/molecule collision, meant that most spectra contained molecular ions (radical cations) from which molecular weight information could be obtained as well as fragment ions which were characteristic of molecular structure.

Because most organic compounds are not volatile, the practice of organic mass spectrometry in the 1970's not infrequently resorted to chemical derivatization - as in the derivatization of amino acids to create methyl esters or alternatively their $\mathrm{N}$-acyl derivatives and also quite often, isotopic labeling, to help elucidate fragmentation mechanisms, ${ }^{85}$ or to allow quantitation by admixture with a known amount of an internal standard and then measurement of a peak ratio by what was essentially an 
isotope dilution experiment. Derivatization was also used to make compounds more amenable to gas chromatography which at that time used normal rather than reverse stationary phases.

The move towards the analysis of non-volatile and especially biological compounds began with the experiments of Hans Beckey on field desorption (FD). ${ }^{86}$ Like so many other ionization methods that would be introduced subsequently, the method was found to be useful empirically long before any real understanding of the process had emerged. The experiment developed from field ionization (FI) which in turn developed from the invention by Müller of the field ion microscope, ${ }^{87}$ the single tungsten atom tipped emitter that was used to create images with unprecedented magnification by the simple electron emission process that made the atom at the tip visible by in the form of an image on the $\mathrm{cm}$ scale recorded on an electron-sensitive detector the magnification factor corresponding to $1 \AA \rightarrow 1 \mathrm{~cm}$ or $10^{8}$. If a vapor phase molecule entered the high electric field around this emitter, an electron could tunnel from a stable orbital in the molecule through the barrier in field and reach the anode. This process created a positively charged ion near a positively charged emitter so it was rapidly accelerated. Beckey's field desorption was a variant on this method in which the sample of interest was placed on the emitter and a combination of heat and the electric field was used to create ions. Presumably heat mobilized the molecules allowing them to reach the tips of the emitters where field ionization occurred. This technique has proved long lasting and commercial field ionization emitters are still available. However, other techniques applicable to the direct ionization of non-volatile compounds appeared the most influential being the 'plasma desorption' (PD) method of Ron Macfarlane. ${ }^{88}$ This experiment used fission fragments of the element californium to create a short lived high energy plasma at the surface of a thin foil on which sample had been deposited. Time of flight was the natural method of mass analysis given the rapid start pulse and was advantageous in compensating for the low overall ion flux, resulting from most fission products lacking the appropriate directionality or timing.

Following the work of Ron Macfarlane, the move to direct ionization methods was represented by the use of secondary ion mass spectrometry (SIMS) for organic analysis. The ejection of secondary ions from surfaces was first observed by J.J. Thomson in $1910 .^{81}$ Heroz and Viehböck performed the first ion/surface experiment involving canal rays (positively charged ions) in 1949 , later coined SIMS. ${ }^{89}$ SIMS uses primary ions (keV energies) to bombard surfaces, sputtering material some of which is ionized (i.e. secondary ions). The earliest experiments focused on elemental analysis and operated in a dynamic mode, causing destruction of the surface. Benninghoven introduced static SIMS which mitigated the damage, examining only virgin surfaces in an essentially non-destructive fashion but limited to the analysis of monolayers. ${ }^{90}$ Static SIMS allowed direct sample analysis of organic and biological compounds within complex mixtures. Winograd and coworkers analyzed organic molecules such as aminobenzoic acid and phenylalanine supported on silver. ${ }^{91}$ Benninghoven analyzed small biologically important compounds and coupled SIMS to time-of-flight (TOF), ${ }^{92}$ again an ideal match of TOF's high transmission efficiency with the smaller ion flux (sputter rate) of static SIMS.

It was soon became apparent that there were three main processes by which ions could be generated in SIMS, as well as in other desorption ionization methods [a term introduced to much criticism about this time but later to become the ' $D$ ' in the widely used MALDI method] ${ }^{93}$ (i) ionization of precharged ions, viz. salts (ii) ionization by cationization (or anionization) and (iii) ionization by electron excitation. 
Because of the importance of the first method, reverse derivatization came to be used as a deliberate method for the creation of a salt so as to improve ionization yields. An early example was the conversion of tertiary to quaternary amines and conversion of ketone and aldehydes to immonium salts by reaction with pyrrolidinium perchlorate. ${ }^{94} \mathrm{~A}$ later example is the characterization of neutral amines through transformation of pyrylium salts to pyridinium salts. ${ }^{95}$ One of the earliest examples of cationization was the attachment of silver cations to compounds like anthracene and p-aminobenzoic acid, a consequence of the use of metallic silver substrates in SIMS, but soon extended by admixture of silver salts (and other metals ${ }^{96}$ ) to the sample. ${ }^{97} \mathrm{This} \mathrm{Ag}^{+}$cationization produces beautiful mass spectra because of the silver isotopic pattern and is particularly useful for binding at olefins. The value of this old reaction has recently seen new appreciation. ${ }^{98}$

Matrix effects on ionization were also appreciated for the first time in the course of organic SIMS. The ability to analyze intact ions from delicate biological samples, nonvolatile, and thermally fragile molecules with SIMS proved a difficult task. The solution came from an unlikely place, the addition of matrix, e.g. ammonium chloride or sodium chloride, to the sample in ratios between 1:20 to 1:50,000 analyte to matrix. ${ }^{99}$ The matrix serves as a 'solvent' which is readily removed upon desorption while simultaneously dissipating excess internal energy. Less fragmentation with higher matrix-to-analyte ratios was experimentally observed for analytes such as quaternary ammonium salts, sucrose, and many amino acids. ${ }^{100}$ It is noteworthy that matrix effects are essential in matrix assisted laser desorption ionization (MALDI) and also in ESI. These two methods of course now form that basis for most structural molecular studies in mass spectrometry. ${ }^{101-103}$

All the ionization methods described previously worked primarily in the positive ion mode; however, the negative ion mode offers the ability to detect specific analytes at low levels. James Lovelock in 1958 developed a method for gas chromatography that allowed for detecting atoms and molecules through electron capture ionization. ${ }^{104}$ This experiment utilized a radioactive source which liberates near thermal energy electrons from a buffer gas. The free electrons interact with low level unoccupied molecular orbitals such as those found in compounds with nitro groups, halogens, and highly conjugated systems. ${ }^{105,106}$ Mass spectrometry exploited this principal by doping different gases, such as methane, isobutane, and methylene chloride, for chemical ionization. ${ }^{107}$ Three types of species are observed in these experiments: $[\mathrm{M}-\mathrm{H}]^{-},[\mathrm{M}+\mathrm{Cl}]^{-}$, and $[\mathrm{M}]^{\circ}$. The first is the result of hydride abstraction, the second occurs by carbon bonding (similar to $\mathrm{SN}_{2}$ ) or attachment through hydrogen bonding, and the radical anion is formed when molecules have positive electron affinities. ${ }^{108}$ Examples of a few complex mixtures analyzed contemporaneously using negative ion formation include, polycyclic aromatic hydrocarbons in refined coal, ${ }^{109}$ ascorbic acid in urine, ${ }^{29}$ and detection of xenobiotic chemicals from biological fluids. ${ }^{108}$ Additional information can be obtained from negative ions through loss of two electrons during charge stripping to give a metastable positive ion that typically dissociates into an ion and a neutral. This method provided rich structural information for aromatic hydrocarbons ${ }^{109}$ and dinitrobenzenes. ${ }^{110}$

\section{Conclusions}

The development of mass spectrometric methods and instrumentation from ca. 1970 - 1980 established the ability to directly analyze complex mixtures. Ionization methods, the recently introduced soft 
ionization allowed a set of neutral molecules to be converted into gaseous ions while maintaining their structural relationship. These developments have played a significant part in altering the complexion of mass spectrometry over the past 50 years. The emphasis on simplicity of chemical analysis has continued and underlies today's ambient ionization sources. Parallel simplifications in instrumentation, especially in the development of small portable mass spectrometers, in combination with MS/MS will allow the direct analysis of complex mixtures to be moved from the lab into the field, the clinic, and the home. This process is now in active development.

\footnotetext{
Glossary

- Direct analysis of complex mixtures - without the need for prior sample preparation and/or chromatography became possible by coupling newly developed soft ionization sources to the MIKE spectrometer in the mid 70's. This provided new areas of application of mass spectrometry including plant materials, biofluids and fuels.

- Direct mixture analysis by MS - while only slowly adopted after its introduction in the mid 70's, has become an important feature of modern mass spectrometry. In retrospect the modern methods of ambient ionization can be seen as a successor method which avoids sample introduction into the vacuum system. .

- Dissociation methods - metastable fragmentation, collision-induced dissociation, and surface-induced dissociation are mentioned briefly with emphasis on their applications direct mixture analysis.

- Ionization methods - the development of ionization methods are discussed as one of the requirements for direct mixture analysis. Transition from electron ionization to softer means of generating ions (e.g. chemical ionization) was pivotal, allowing the generation of ions as surrogates for molecules.

- MIKES - mass-analyzed ion kinetic energy spectrometer, a reversed geometry two-sector instrument that initiated a great deal of activity in ion structure, ion chemistry and ion thermochemistry. New understanding of the dynamics of unimolecular reactions came from kinetic energy release measurements. Charge changing as well as dissociative collisions were an early topic of intense interest.

- Scan Types - recognition of the full range of MS/MS scan types developed over time. The various scans improved qualitative and quantitative analysis of complex mixtures. Single reaction monitoring (SRM) and multiple reaction monitoring (MRM) have become premier method of quantitation. Fundamentals of MS/MS scan modes are discussed in regards to applicability to complex mixture analysis.
}

\section{Acknowledgements}

Most of the work described here was done with financial support from the National Science Foundation or the US Department of Energy. Currently, these agencies support this laboratory through NSF CHE 1307264 and DOE Basic Energy Sciences. The work at Purdue is that of a large number of people who are listed elsewhere http://aston.chem.purdue.edu and for whose efforts this is but a feeble acknowledgement. Special acknowledgement goes to the people of ThermoFisher and its ancestral companies for their support of the scientific efforts at Purdue University described here.

\section{References}

1 Beynon, J. \& Cooks, R. Ion Kinetic Energy Spectrometry. Research-Development 22 (1971).

2 Wachs, T., Bente III, P. F. \& McLafferty, F. Simple modification of a commercial mass spectrometer for metastable data collection. International Journal of Mass Spectrometry and lon Physics 9, 333-341 (1972).

3 White, F. A. \& Wood, G. M. Mass Spectrometry: Applications in science and engineering. (Wiley New York, 1986).

4 Futrell, J. H. \& Tiernan, T. O. Ion-Molecule Reactions. Science 162, 415-422, doi:10.2307/1725276 (1968). 

mass-analyzed ion kinetic energy (MIKE) spectrometer. Analytical Chemistry 45, 1023A-1031A (1973).

6 Amy, J., Baitinger, W. \& Cooks, R. Building mass spectrometers and a philosophy of research. Journal of the American Society for Mass Spectrometry 1, 119-128, doi:10.1016/10440305(90)85047-P (1990).

7 Herschbach, D. R. Reactive collisions in crossed molecular beams. Discussions of the Faraday Society 33, 149-161 (1962).

8 Hipple, J., Fox, R. \& Condon, E. Metastable ions formed by electron impact in hydrocarbon gases. Physical Review 69, 347 (1946).

9 Cooks, R. G., Beynon, J., Caprioli, R. \& Lester, G. Metastable Ions. 296 (American Elsevier Publishing, 1973).

10 Shukla, A. K. \& Futrell, J. H. Tandem mass spectrometry: dissociation of ions by collisional activation. Journal of Mass Spectrometry 35, 1069-1090 (2000).

11 Laskin, J. \& Lifshitz, C. Kinetic energy release distributions in mass spectrometry. Journal of mass spectrometry 36, 459-478 (2001).

12 Bertrand, M., Beynon, J. \& Cooks, R. Isotope effects upon kinetic energy release in metastable ion fragmentations. International Journal of Mass Spectrometry and Ion Physics 9, 346-350 (1972).

13 Fales, H. \& Wright, G. Detection of chirality with the chemical ionization mass spectrometer." Meso" ions in the gas phase. Journal of the American Chemical Society 99, 2339-2340 (1977).

14 Tao, W. A. \& Cooks, R. G. Peer Reviewed: Chiral analysis by MS. Analytical Chemistry 75, 25 A-31 A, doi:10.1021/ac0312110 (2003).

15 McLuckey, S., Cameron, D. \& Cooks, R. Proton affinities from dissociations of proton-bound dimers. Journal of the American Chemical Society 103, 1313-1317 (1981).

16 Beynon, J., Bertrand, M. \& Cooks, R. Metastable loss of nitrosyl radical from aromatic nitro compounds. Journal of the American Chemical Society 95, 1739-1745 (1973).

17 Kruger, T., Cooks, R., McLaughlin, J. \& Ranieri, R. Identification of alkaloids in crude extracts by mass-analyzed ion kinetic energy spectrometry. The Journal of Organic Chemistry 42, 41614162, doi:10.1021/jo00445a044 (1977).

18 Yost, R. \& Enke, C. Selected ion fragmentation with a tandem quadrupole mass spectrometer. Journal of the American Chemical Society 100, 2274-2275 (1978).

19 Yost, R. \& Enke, C. Triple quadrupole mass spectrometry for direct mixture analysis and structure elucidation. Analytical chemistry 51, 1251-1264 (1979).

20 Hunt, D. F., Shabanowitz, J. \& Giordani, A. B. Collision activated decompositions in mixture analysis with a triple quadrupole mass spectrometer. Analytical Chemistry 52, 386-390 (1980).

21 Hunt, D. F., Giordani, A., Rhodes, G. \& Herold, D. A. Mixture analysis by triple-quadrupole mass spectrometry: metabolic profiling of urinary carboxylic acids. Clinical chemistry 28, 2387-2392 (1982).

22 Hunt, D. F. \& Shabanowitz, J. Determination of organosulfur compounds in hydrocarbon matrixes by collision activated dissociation mass spectrometry. Analytical Chemistry 54, 574-578 (1982).

23 McLafferty, F., Bente, P., Kornfeld, R., Tsai, S.-C. \& Howe, I. Metastable ion characteristics. XXII. Collisional activation spectra of organic ions. Journal of the American Chemical Society 95, 21202129 (1973).

24 McLafferty, F. W. Tandem Mass Spectrometry. Science 214, 280-287, doi:10.2307/1686862 (1981). 

Tandem Mass Spectrometry. (Wiley-VCH Verlag GmbH, 1989).

26 Kruger, T.-L., Litton, J., Kondrat, R.-W. \& Cooks, R. Mixture analysis by mass-analyzed ion kinetic energy spectrometry. Analytical Chemistry 48, 2113-2119 (1976).

27 Kondrat, R., Cooks, R. \& McLaughlin, J. Alkaloids in whole plant material: direct analysis by kinetic energy spectrometry. Science 199, 978-980 (1978).

28 Kondrat, R., McClusky, G. \& Cooks, R. Direct mass spectrometric mixture analysis by negative chemical ionization/mass-analyzed ion kinetic energy spectrometry. Analytical Chemistry 50, 1222-1223 (1978).

29 McClusky, G. A., Kondrat, R. W. \& Cooks, R. G. Direct mixture analysis by mass-analyzed ion kinetic energy spectrometry using negative chemical ionization. Journal of the American Chemical Society 100, 6045-6051 (1978).

30 Kondrat, R., McClusky, G. \& Cooks, R. Multiple reaction monitoring in mass spectrometry/mass spectrometry for direct analysis of complex mixtures. Analytical Chemistry 50, 2017-2021, doi:10.1021/ac50036a020 (1978).

31 Kruger, T., Kondrat, R., Joseph, K. \& Cooks, R. Identification of individual steroids in biological matrices by mass-analyzed ion kinetic energy spectrometry. Analytical biochemistry 96, 104-112 (1979).

32 Zakett, D., Shaddock, V.-M. \& Cooks, R. Analysis of coal liquids by mass-analyzed ion kinetic energy spectrometry. Analytical Chemistry 51, 1849-1852 (1979).

33 Youssefi, M., Cooks, R. \& McLaughlin, J. Mapping of cocaine and cinnamoylcocaine in whole coca plant tissues by MIKES. Journal of the American Chemical Society 101, 3400-3402 (1979). Cooks, R. G. Mixture Analysis by Mass Spectrometry. NBS Special Publication, 519 (1979). Glish, G., Shaddock, V., Harmon, K. \& Cooks, R. Rapid analysis of complex mixtures by mass spectrometry/mass spectrometry. Analytical Chemistry 52, 165-167 (1980).

36 Unger, S., Cooks, R., Mata, R. \& McLaughlin, J. Chemotaxonomy of columnar Mexican cacti by mass spectrometry/mass spectrometry. Journal of natural products 43, 288-293 (1980).

37 Zakett, D., Cooks, R. \& Fies, W. A double quadrupole for mass spectrometry/mass spectrometry. Analytica Chimica Acta 119, 129-135 (1980).

38 Gush, G., Hemberger, P. \& Cooks, R. Ion structure determinations and ion-molecule reactions by double quadrupole mass spectrometry. Analytica Chimica Acta 119, 137-144 (1980).

39 Zakett, D. \& Cooks, R. in New Approaches in Coal Chemistry, ACS Symposium Series Ch. 16, 267-288 (1981).

40 Burinsky, D. J., Cooks, R. G., Chess, E. K. \& Gross, M. L. Consecutive reactions in triple analyzer mass spectrometry and applications to mixture analysis. Analytical Chemistry 54, 295-299 (1982).

41 Pummangura, S., McLaughlin, J., Davis, D. \& Cooks, R. Cactus Alkaloids. XLIX. New Trace Alkaloids (Dehydrosalsolidine and Heliamine) From the Saguaro, Carnegiea gigantea, and Confirmation by Mikes (MS/MS). Journal of Natural Products 45, 277-282 (1982).

42 Davis, D. V. \& Cooks, R. G. Direct characterization of nutmeg constituents by mass spectrometrymass spectrometry. Journal of Agricultural and Food Chemistry 30, 495-504 (1982).

43 Ciupek, J., Zakett, D., Cooks, R. \& Wood, K. High and low energy collision mass spectrometry/mass spectrometry of aza and amino polynuclear aromatic compounds in coalderived liquids. Analytical Chemistry 54, 2215-2219 (1982).

44 Cooks, R. in Collision Spectroscopy Vol. 1 Ch. 7, 360 (1978).

45 Tunitskii, N., Kupriyanov, S. \& Perov, A. Mass spectra of molecules and radiation chemistry. Bulletin of the Academy of Sciences of the USSR, Division of chemical science 11, 1857-1864 (1962). 
Farncombe, M., Mason, R.-S., Jennings, K. \& Scrivens, J. Linked scanning and metastable ion mapping. International Journal of Mass Spectrometry and lon Physics 44, 91-107 (1982).

47 Barber, M. \& Elliott, R. M. Comparison of Metastable Spectra from Single and Double Focusing Mass Spectrometers. Proceedings of the 12th Annual Conference on Mass Spectrometry and Allied Topics, 150-157 (1964).

48 Weston, A. F., Jennings, K. R., Evans, S. \& Elliott, R. M. The observation of metastable transitions in a double-focussing mass spectrometer using a linked scan of the accelerating and electricsector voltages. International Journal of Mass Spectrometry and Ion Physics 20, 317-327, doi:http://dx.doi.org/10.1016/0020-7381(76)80158-1 (1976).

49 Zakett, D., Schoen, A., Kondrat, R. \& Cooks, R. Selected fragment scans of mass spectrometers in direct mixture analysis. Journal of the American Chemical Society 101, 6781-6783, doi:10.1021/ja00516a064 (1979).

50 Schwartz, J. C., Wade, A. P., Enke, C. G. \& Cooks, R. G. Systematic delineation of scan modes in multidimensional mass spectrometry. Analytical chemistry 62, 1809-1818, doi:10.1021/ac00216a016 (1990).

51 Cooks, R., Ast, T. \& Mabud, M. A. Collisions of polyatomic ions with surfaces. International Journal of Mass Spectrometry and lon Processes 100, 209-265 (1990).

52 Cyriac, J., Pradeep, T., Kang, H., Souda, R. \& Cooks, R. Low-energy ionic collisions at molecular solids. Chemical reviews 112, 5356-5411 (2012).

53 Johnson, G. E., Hu, Q. \& Laskin, J. Soft Landing of Complex Molecules on Surfaces. Annual Review of Analytical Chemistry 4, 83-104 (2011).

54 Wright, A. D., Despeyroux, D., Jennings, K. R., Evans, S. \& Riddoch, A. Surface-induced dissociation mass spectra of protonated peptides using a four-sector mass spectrometer. Organic mass spectrometry 27, 525-526 (1992).

55 Cooks, R., Terwilliger, D., Ast, T., Beynon, J. \& Keough, T. Surface modified mass spectrometry. Journal of the American Chemical Society 97, 1583-1585 (1975).

56 Mabud, M. A., Dekrey, M. J. \& Graham Cooks, R. Surface-induced dissociation of molecular ions. International journal of mass spectrometry and ion processes 67, 285-294 (1985).

57 Laskin, J., Denisov, E. \& Futrell, J. Comparative study of collision-induced and surface-induced dissociation. 2. Fragmentation of small alanine-containing peptides in FT-ICR MS. The Journal of Physical Chemistry B 105, 1895-1900 (2001).

58 Wörgötter, R. et al. Surface-induced reactions and decomposition of the benzene molecular ion C6H6+: Product ion intensities, angular and translational energy distributions. International Journal of Mass Spectrometry and lon Processes 174, 53-62, doi:http://dx.doi.org/10.1016/S0168-1176(97)00289-9 (1998).

59 Franchetti, V., Solka, B., Baitinger, W., Amy, J. \& Cooks, R. Soft landing of ions as a means of surface modification. International Journal of Mass Spectrometry and lon Physics 23, 29-35 (1977).

60 Miller, S., Luo, H., Pachuta, S. \& Cooks, R. Soft-landing of polyatomic ions at fluorinated selfassembled monolayer surfaces. Science 275, 1447-1450 (1997).

61 Peng, W.-P. et al. Redox chemistry in thin layers of organometallic complexes prepared using ion soft landing. Physical Chemistry Chemical Physics 13, 267-275 (2011).

62 Ouyang, Z. et al. Preparing protein microarrays by soft-landing of mass-selected ions. Science 301, 1351-1354 (2003).

63 Deng, Z. et al. A Close Look at Proteins: Submolecular Resolution of Two-and ThreeDimensionally Folded Cytochrome c at Surfaces. Nano letters 12, 2452-2458 (2012).

64 Rauschenbach, S. et al. Electrospray ion beam deposition of clusters and biomolecules. Small 2, 540-547 (2006). 
Lehman, T. A. \& Bursey, M. M. Ion Cyclotron Resonance Spectrometry. (John Wiley \& Sons Inc, 1976).

66 Brodbelt, J. S. Analytical applications of ion-molecule reactions. Mass Spectrometry Reviews 16, 91-110 (1997).

67 Armentrout, P. \& Beauchamp, J. The chemistry of atomic transition-metal ions: insight into fundamental aspects of organometallic chemistry. Accounts of Chemical Research 22, 315-321 (1989).

68 Keesee, R. \& Castleman Jr, A. Thermochemical Data on Gas-Phase Ion-Molecule Association and Clustering Reactions. Journal of physical and chemical reference data 15, 1011-1071 (1986).

69 Wysocki, V. H., Joyce, K. E., Jones, C. M. \& Beardsley, R. L. Surface-induced dissociation of small molecules, peptides, and non-covalent protein complexes. Journal of the American Society for Mass Spectrometry 19, 190-208 (2008).

70 Grill, V., Shen, J., Evans, C. \& Cooks, R. G. Collisions of ions with surfaces at chemically relevant energies: instrumentation and phenomena. Review of Scientific Instruments 72, 3149-3179, doi:10.1063/1.1382641 (2001).

71 Fedor, D. \& Cooks, R. Angle resolved mass spectrometry with a reversed geometry spectrometer. Analytical Chemistry 52, 679-682, doi:10.1021/ac50054a021 (1980).

72 Horning, S., Vincenti, M. \& Cooks, R. Angular dependence of internal energy distributions of activated Fe (CO) 5. cntdot.+ and W (CO) 6. cntdot.+ ions. The contributions of vibrational and electronic excitation mechanisms in kiloelectron volt collisions. Journal of the American Chemical Society 112, 119-126 (1990).

73 Freidrich, B. \& Herman, Z. Dynamics of ion-molecule processes: A crossed-beam study of the reaction $\mathrm{B}+(3 \mathrm{P})+\mathrm{H} 2 \rightarrow \mathrm{BH}++\mathrm{H}$. Chemical Physics 69, 433-442, doi:http://dx.doi.org/10.1016/0301-0104(82)88081-6 (1982).

74 Winger, B. et al. Hybrid BEEQ tandem mass spectrometer for the study of ion/surface collision processes. Review of scientific instruments 63, 5613-5625 (1992).

75 Chupka, W. A. Effect of Unimolecular Decay Kinetics on the Interpretation of Appearance Potentials. The Journal of Chemical Physics 30, 191-211, doi:doi:http://dx.doi.org/10.1063/1.1729875 (1959).

76 Rosenstock, H. M., Wallenstein, M., Wahrhaftig, A. L. \& Eyring, H. Absolute rate theory for isolated systems and the mass spectra of polyatomic molecules. Proceedings of the National Academy of Sciences of the United States of America 38, 667 (1952).

77 Rabinovitch, B. S. \& Setser, D. W. in Advances in Photochemistry Vol. 3 1-82 (John Wiley \& Sons, Inc., 1964).

78 Vékey, K., Brenton, A. G. \& Beynon, J. H. Electron capture-induced decomposition (ECID): A new method to study electron-capture collisions. International Journal of Mass Spectrometry and lon Processes 70, 277-300 (1986).

79 Wysocki, V. H., Kenttämaa, H. I. \& Cooks, R. G. Internal energy distributions of isolated ions after activation by various methods. International journal of mass spectrometry and ion processes $\mathbf{7 5}$, 181-208 (1987).

80 Lambert, J. B., Shurvell, H. F., Lightner, D. A. \& Cooks, R. G. Introduction to organic spectroscopy. (Macmillan New York, 1987).

81 Thomson, J. J. Bakerian lecture: Rays of positive electricity. Proceedings of the Royal Society of London. Series A 89, 1-20 (1913).

82 Beynon, J., Caprioli, R., Baitinger, W. \& Amy, J. The ion kinetic energy spectra of some aromatic hydrocarbons. Organic Mass Spectrometry 3, 455-477 (1970). 

spectrometer for doubly charged ions. Organic Mass Spectrometry 18, 561-567, doi:10.1002/oms.1210181213 (1983).

84 Sleno, L. The use of mass defect in modern mass spectrometry. Journal of mass spectrometry 47, 226-236, doi:10.1002/jms.2953 (2012).

85 Budzikiewicz, H., Djerassi, C. \& Williams, D. H. 271 (Holden-Day, 1964).

86 Beckey, H.-D. Principles of field ionization and field desorption mass spectrometry. (Pergamon Press Oxford, 1977).

87 Müller, E. W. Field ionization and field ion microscopy. Advances in electronics and electron physics 13, 83-179 (1960).

88 Macfarlane, R. \& Torgerson, D. Californium-252 plasma desorption mass spectroscopy. Science 191, 920-925, doi:10.1126/science.1251202 (1976).

89 Herzog, R. \& Viehböck, F. Ion source for mass spectrography. Physical Review 76, 855 (1949).

90 Benninghoven, A., Jaspers, D. \& Sichtermann, W. Secondary-ion emission of amino acids. Applied physics 11, 35-39 (1976).

91 Grade, H., Winograd, N. \& Cooks, R. Cationization of organic molecules in secondary ion mass spectrometry. Journal of the American Chemical Society 99, 7725-7726, doi:10.1021/ja00465a062 (1977).

92 Benninghoven, A. \& Sichtermann, W. Secondary ion mass spectrometery: A new analytical technique for biologically important compounds. Organic Mass Spectrometry 12, 595-597, doi:10.1002/oms.1210120914 (1977).

93 Tanaka, K. et al. Protein and polymer analyses up to $\mathrm{m} / \mathrm{z} 100000$ by laser ionization time of flight mass spectrometry. Rapid Communications in Mass Spectrometry 2, 151-153 (1988).

94 Busch, K., Unger, S., Vincze, A., Cooks, R. \& Keough, T. Desorption ionization mass spectrometry: sample preparation for secondary ion mass spectrometry, laser desorption, and field desorption. Journal of the American Chemical Society 104, 1507-1511, doi:10.1021/ja00370a009 (1982).

95 Busch, K. L. et al. Characterization of organic cations of synthetic interest by desorption ionization and tandem mass spectrometry. The Journal of Organic Chemistry 49, 764-769, doi:10.1021/jo00179a006 (1984).

96 Day, R., Unger, S. \& Cooks, R. Formation of metal chelates in secondary ion mass spectrometry. Comparisons with solution chemistry. Journal of the American Chemical Society 101, 499-501 (1979).

97 Grade, H. \& Cooks, R. Secondary ion mass spectrometry. Cationization of organic molecules with metals. Journal of the american chemical society 100, 5615-5621 (1978).

98 Espy, R. D., Wleklinski, M., Yan, X. \& Graham Cooks, R. Beyond the flask: Reactions on the fly in ambient mass spectrometry. TrAC Trends in Analytical Chemistry (2014).

99 Busch, K. L., Hsu, B. H., Xie, Y. X. \& Cooks, R. G. Matrix effects in secondary ion mass spectrometry. Analytical Chemistry 55, 1157-1160 (1983).

100 Liu, L. K., Busch, K. L. \& Cooks, R. Matrix-assisted secondary ion mass spectra of biological compounds. Analytical Chemistry 53, 109-113 (1981).

101 Yamashita, M. \& Fenn, J. B. Electrospray ion source. Another variation on the free-jet theme. The Journal of Physical Chemistry 88, 4451-4459 (1984).

102 Fenn, J. Electrospray ionization mass spectrometry: How it all began. Journal of biomolecular techniques: JBT 13, 101 (2002).

103 Karas, M., Bachmann, D., Bahr, U. e. \& Hillenkamp, F. Matrix-assisted ultraviolet laser desorption of non-volatile compounds. International journal of mass spectrometry and ion processes 78, 5368 (1987). 
104 Lovelock, J. A sensitive detector for gas chromatography. Journal of Chromatography A 1, 35-46 (1958).

105 Lovelock, J. The electron capture detector: Theory and practice. Journal of Chromatography $A$ 99, 3-12 (1974).

106 Trainor, T. M. \& Vouros, P. Electron capture negative ion chemical ionization mass spectrometry of derivatized chlorophenols and chloroanilines. Analytical chemistry 59, 601-610 (1987).

107 Hunt, D. F. \& Crow, F. W. Electron capture negative ion chemical ionization mass spectrometry. Analytical Chemistry 50, 1781-1784 (1978).

108 Dougherty, R. Negative chemical ionization mass spectrometry: applications in environmental analytical chemistry. Biological Mass Spectrometry 8, 283-292 (1981).

109 Zakett, D., Ciupek, J. \& Cooks, R. Determination of polycyclic aromatic hydrocarbons in solventrefined coal by negative chemical ionization-charge inversion mass spectrometry/mass spectrometry. Analytical Chemistry 53, 723-726 (1981).

110 Bowie, J. \& Blumenthal, T. The + E collision induced mass spectra from negative ions. Journal of the American Chemical Society 97, 2959-2962 (1975). 